\title{
End-of-Life Decisions in Intensive Care Units in Croatia-Pre COVID-19 Perspectives and Experiences From Nurses and Physicians
}

\author{
Marko Ćurković • Lovorka Brajković • \\ Ana Jozepović · Dinko Tonković · Željko Župan • \\ Nenad Karanović • Ana Borovečki (i)
}

Received: 14 January 2021 / Accepted: 16 July 2021 / Published online: 23 September 2021

(C) Journal of Bioethical Inquiry Pty Ltd. 2021

\begin{abstract}
Healthcare professionals working in intensive care units (ICUs) are often involved in endof-life decision-making. No research has been done so far about these processes taking place in Croatian ICUs. The aim of this study was to investigate the perceptions, experiences, and challenges healthcare professionals face when dealing with end-of-life decisions in ICUs in Croatia. A qualitative study was performed using professionally homogenous focus groups of ICU nurses and physicians (45 in total) of diverse professional and clinical backgrounds at three research sites (Zagreb, Rijeka, Split). In total, six institutions at the tertiary level of healthcare were included. The constant comparative analysis method
\end{abstract}

M. Ćurković

University Psychiatric Hospital Vrapče, Bolnička cesta 32, 10090 Zagreb, Croatia

M. Ćurković · A. Jozepović · D. Tonković ·

A. Borovečki ( $\square)$

School of Medicine, University of Zagreb, Šalata 2, 10000 Zagreb, Croatia

e-mail: abor@mef.hr

\section{Brajković}

Department for Psychology, Faculty of Croatian Studies, University of Zagreb, Borongajska cesta 83d, 10000 Zagreb, Croatia

D. Tonković

Department of Anesthesiology, Reanimatology and Intensive care, University Hospital Center Zagreb, Kišpatićeva ulica 12, 10000 Zagreb, Croatia was used in the analysis of the data. Differences were found between the perceptions and experiences of nurses and physicians in relation to end-of-life decisions. Nurses' perceptions were more focused on the context and features of immediate care, while physicians' perceptions also included the wider sociocultural context. However, the critical issues these specific professional groups face when dealing with end-of-life decisions seem to overlap. A high variability of practices, both between individual practitioners and between different organizational units, was omnipresent. The lack of adequate legal, professional, and clinical guidelines was commonly expressed as one of the most critical source of difficulties.

\section{Ž. Župan}

Department of Anesthesiology, University Hospital Center Rijeka, Krešimirova ulica 42, 51000 Rijeka, Croatia

\section{Ž. Župan}

School of Medicine, University of Rijeka, Ulica Braće Branchetta 20/1, 51000 Rijeka, Croatia

N. Karanović

Department of Anesthesiology, University Hospital Center Split, Spinčićeva ulica 1, 21000 Split, Croatia

N. Karanović

School of Medicine, University of Split, Šoltanska ulica 2, 21000 Split, Croatia 
Keywords Intensive care units $\cdot$ Critical care $\cdot$ Endof-life $\cdot$ Decision-making $\cdot$ Nurses $\cdot$ Physicians

\section{Introduction}

Healthcare is becoming increasingly technologically advanced, creating complicated end-of-life issues (Curtis and Vincent 2010; Sprung et al. 2014). This is most evident in the setting of intensive care units (hereinafter: ICU), where healthcare professionals are often involved in end-of-life decisions (Flannery, Ramjan, and Peters 2016; Westphal and McKee 2009). End-of-life decisions in ICUs include decisions about withholding or withdrawing potentially life-prolonging treatment and decisions about alleviation of pain and other symptoms with possible life-shortening effects (Sprung et al. 2014; Joynt et al. 2015; Downar et al. 2016). However, although these issues are commonly faced in the ICU setting, it seems that healthcare professionals are not well equipped to deal with end-of-life decisions and their consequences (St Ledger, et al. 2012; Deyaert, et al. 2014; Latour, Fulbrook, and Albarran 2009; McMillen 2008; Forte, et al. 2012; van Mol, et al. 2015; Lief, et al. 2018.). Among the most often noted issues faced within end-of-life decision-making, physicians and nurses express poor communication, role ambiguity, and the lack of clear guidelines (Deyaert, et al. 2014; Latour, Fulbrook, and Albarran 2009; Wilkinson, Truog, and Savulescu 2016). This has recently been additionally complicated by the challenges that ICU physicians face during the COVID-19 pandemic (Orfali 2020; Anderson Shaw and Zar 2020).

The Republic of Croatia, the youngest member of European Union, is an ageing society where a significant proportion of deaths occur within healthcare institutions, e.g. ICUs. In Croatia there is a relatively high proportion of religious people, according to the census of 2011 (91.37 per cent members of Christian denominations of which 86.28 per cent Catholic; 1.44 per cent Muslim, and 0.01 per cent Jewish).

Data from different Croatian studies describe the model of physician-patient relationships in Croatia as the shared decision-making model, whereby physicians explain the patients' health condition, disease, and the course and purpose of treatment. However, there is still considerable room for improvement, especially when it comes to adequate communication about treatment methods, and the risks, side effects, and complications of treatment (Vucemilo et al. 2013; Vucemilo et al. 2016).

According to the Croatian Act on the Protection of Patients' Rights, for patients without the legal capacity to give consent (e. g. an unconscious patient, which is often the case in the ICU setting, or minors), except in the case of urgent medical intervention, consent is given by the legal representative. According to the same Act on the Protection of Patients' Rights, patients have the right to refuse a diagnostic or therapeutic procedure, except in the case of urgent medical intervention, the failure of which would endanger the life and health of the patient or cause permanent damage to their health. No forms of anticipatory decisionmaking (e.g. living wills, do-not-resuscitate orders) by patients are regulated by law in Croatia except in the Act on Human Organ Transplantation for Medical Purposes, where anticipatory decision-making is permitted if a person wants to opt-out from the donor pool (Hrstic 2016). In the Republic of Croatia euthanasia and physician-assisted suicide are illegal and are prescribed as criminal offences in the Criminal Code, with a penalty of up to three years in prison (Sladic 2015).

In the Code of Medical Ethics and Deontology of the Croatian Medical Chamber and the Croatian Medical Association, in a short paragraph on the dying patient, the following recommendation is found: "Continuing intensive treatment of a patient in an irreversible final condition is not medically necessarily well-founded, and excludes the right of the dying patient to a dignified death."

Research by Sorta-Bilajac et al. (2008) indicates that most frequent ethical dilemmas experienced by Croatian physicians and nurses in everyday practice are connected to the uncertain or impaired decisionmaking capacity of patients and withdrawing or withholding treatment at the end of life.

Jukic et al. (2016) conducted research in ICUs in Croatia through a retrospective patients' chart review in order to investigate cases of potentially medically futile treatment of deceased patients in intensive care units. The analysis indicated that a certain percentage of patients did not need prolonged ICU treatment. Instead, they should have been treated in a palliative care unit. One of the reasons for this situation was the lack of palliative care units, the lack of working protocols, 
algorithms, and guidelines to help physicians decide, and the lack of experienced ethics services which would help ICU staff make decisions about potential cases of medical futility.

In 2017, a project funded by the Croatian Science Foundation, entitled Values and Decisions at the End of Life (VAL-DE-END) was launched. The aim of this project is to study decision-making related to the end of life in intensive care units in hospitals at tertiary level healthcare (clinics, clinical hospitals, and clinical hospital centres) in Croatia. The tertiary level healthcare intuitions were chosen because of the complexity of the cases that they deal with in their everyday practice. In order to achieve these goals, a multidisciplinary research team was created (philosophers, theologians, IUC physicians, lawyers, psychologists, psychiatrist, palliative care experts) to perform a series of retrospective and prospective studies, of quantitative and qualitative types, during the project duration. The project has two tracks: one dealing with adult ICUs and one dealing with paediatric ICUs, as these are two very different settings with different sets of issues at stake. The proposed project methodology had already been tested in a similar study by Groselj et al. (2014) in the neighboring country Slovenia, with which Croatia shares a common socio-cultural background and past. One of the outputs of the project is a proposal of guidelines for end-oflife decision-making in intensive care units in Croatia, similar to those already proposed in Slovenia (Grosek, Orazem, and Groselj 2018). Two project members were invited to participate in the work of a recently formed working-group on a national level that will be involved in drafting end-of-life guidelines on the national level.

This paper presents the focus group research conducted in adult ICUs in Croatia as part of the VALDE-END project. The main aim was to study decisionmaking related to end-of-life in ICUs in tertiary level healthcare institutions in the Republic of Croatia, from the perspective of front-line healthcare professionals.

\section{Methodology}

Design

This study was a qualitative study based on focus group interviews with physicians and nurses working in adult ICUs.
Setting

The study was conducted in adult ICUs in institutions at the tertiary level of healthcare (clinics, clinical hospitals, and clinical hospital centres) in the three largest cities in the Republic of Croatia: Zagreb, Rijeka, and Split. In Split and Rijeka the focus groups were conducted at two different locations each, since the tertiary institutions there operate at two separate locations. In Zagreb, which unlike Split and Rijeka, has more than one tertiary healthcare institution, the research was conducted at: Zagreb Clinical Hospital Center, Sestre Milosrdnice Clinical Hospital Center, Dubrava Clinical Hospital, and Sveti Duh Clinical Hospital. Ethical approval was obtained from the ethics committees of all the institutions involved in the research (University Hospital Centre Zagreb 2/21AG 16.5.2017; Rijeka Clinical Hospital Centre 2170-29-02/15-17-2 23.4. 2017; University Hospital Split 2181-147-01/06/M.S.-17-2, 20.4.2017; Sestre Milosrdnice Clinical Hospital Center EP-7259/1713, 5.5.2017; Sveti Duh Clinical Hospital 01-194, 1.6.207; Dubrava Clinical Hospital 17.5.2017. no number provided), as well as from the ethics committee of the School of Medicine, University of Zagreb (380-59-10106-17-100/208, 13.7.2017). The initial intention was also to include the fourth largest city, Osijek in the eastern part of the Croatia, which also has a tertiary healthcare institution, Osijek Clinical Medical Center. However, the approval of the ethics committee of Clinical Medical Center Osijek was never received, nor did we receive any reply to our officially submitted request with the supporting documents. The focus groups were conducted between December 2018 and July 2019, before the start of the COVID-19 pandemic.

\section{Participants}

Focus group sessions were conducted using purposive sampling, with two healthcare professional groups: specialist physicians and nurses. These two groups are also the ones that are usually on staff in the ICUs in Croatia, while other healthcare professionals e.g. physiotherapists, are not part of ICU departments but come on a regular basis from other departments (Degoricija et al. 2002). The members of the project team, who are physicians in ICUs, approached their 
colleagues and asked them to ask nurses and physicians who were eligible for the focus group research, according to our inclusion criteria, to participate in the research. Participation in the research was voluntary and anonymous. The main inclusion criterion for the physicians and nurses for the focus group sessions was at least one year of working experience in ICUs. Where possible the groups had half of the nurses and physicians with less than five years of work experience in the ICU and half of them with more than five years' work experience. We tried to ensure a gender balance among both physicians and nurses. In each nursing focus group session we included nurses with different educational backgrounds that may be found in Croatia in similar proportions, if it was possible (those with secondary education and those with a higher or university degree). We also aimed at having physicians and nurses from all organizational types of ICUs that can be found in healthcare institutions in Croatia, since some institutions have "stand-alone" ICU units and some ICU units are linked to internal medicine, neurological, or surgical departments. All study participants signed written informed consent, after being fully informed about the specific and overall research project methodology and goals.

\section{Data Collection}

Data collection was conducted by two experienced focus group moderators (author 1 M.C and author 2 L.B.). The questions were informed by a review of the scientific literature on end-of-life and medical ethics and through iterative discussion and external validation within the multidisciplinary research project team. Certain questions, related to intentional life-terminating actions, were intentionally omitted as these actions are strictly forbidden by the local legislative and could provoke a defensive reaction in participants, disabling open discussion (Table 1). During the focus groups sessions, interviewers probed participants for their interpretation of the questions. They were probed on how they formulated their responses to these questions. All focus group discussions were conducted in the local language. Data were audiorecorded and transcribed verbatim. All collected data were anonymized and stored according to the Croatian Law on Data Protection (NN 106/2012) and EU Data Protection Directive 95/46/EC.

\section{Data Analysis}

Data were analysed using the constant comparative analysis method, informed by constructivist grounded theory and grounded theory methods (Bowen 2008; Denzin and Lincoln 1994; Glaser and Strauss 2009). The constant comparative analysis method requires the researcher to take one piece of data and compare it to all other pieces of data. The analysis of the data is cyclical, consisting of initial coding, reflecting, and re-reading, then sorting and sifting through the codes to discover patterns and themes (Grove 1988). In our case, the transcripts of focus group discussions were coded by reading each document and attributing codes to sentences, paragraphs, or sections. Data analysis was inductive in order to understand individual views and perceptions. New codes were added during subsequent reading of transcripts and data when it was not initially clear how they should be coded. The coded sections established were compared with similarly coded segments to ensure consistency. After the final coding was completed, files were compiled with the title of the code and stored in files labelled with each code. The codes that had common elements were merged to form subthemes and main themes. The reconstruction of the data was then presented to the project team members, who are physicians and experts in intensive care medicine and were also present during the focus group discussions, in order to determine whether the proposed data reconstruction was a reasonable account of the discussion that took place in the focus groups (Hewitt-Taylor 2001).

\section{Results}

There were forty-five focus group participants. Twenty-two physicians, specialists in intensive care medicine, took part in six focus group sessions (one in Zagreb, two in Rijeka, and three in Split), six physicians in Zagreb, nine in Rijeka and seven in Split. There were twenty-three nurses who took part in four focus group sessions (two sessions took place in Rijeka, with eight nurses in Zagreb, eight in Rijeka, and seven in Split). More than one focus group session was held either because the healthcare initiation operates on two separate sites (Rijeka) or because of the high workload and staff shortages (Split). Altogether eleven physicians and twelve nurses came from "stand-alone" ICU units and eleven physicians 
Table 1 Focus group discussion guide

Discussion Subsets Discussion Structure

A. General introduction General introduction to focus group discussion and explanation

B. Opening

Let's start by telling us your name, years of service, and how many of your colleagues you share your shift with on a normal working day?

C. Introduction

You've probably heard the term end-of-life decisions often, but what exactly does that term mean to you?

What do you mean by cessation of active treatment?

- possibilities (forgoing / non-initiation, interruption / cessation $=>$ cessation of active treatment; palliative care; conscious, active, intentional action with the purpose of killing / cessation of life $=>$ active shortening of life)

- procedures (resuscitation, artificial ventilation; extubation; antibiotics; hydration $=>$ ordinary / usual extraordinary / unusual)

D. Transition

How often do you encounter this in your daily work?

Can you give examples of situations you have encountered?

E. Main discussion $\quad$ 1. Discussion and decisions

What most often triggers a discussion about cessation of active treatment (forgoing / cessation) or end-oflife decisions?

- Who most often initiates the discussion?

- Who leads it, encourages it?

- Who participates in the discussion?

- Who usually decides to stop active treatment?

What/who are individuals guided by when deciding to discontinue active treatment?

- patients, family members, legal representatives; doctors; nurses; someone else [e.g. ethics committee, court]

How much is your opinion valued?

How is the opinion of the patient, his relatives or legal representatives evaluated?

- of other physicians

- of nurses

What causes disagreement in end-of-life decisions?

What do you do when you do not agree with the decision to stop active treatment?

What do you do when you think your current treatment is futile?

What do you do when you think that the wishes of the patient or his relatives are unfounded?

How often is it necessary to revise an already made decision?

2. Implementation of the decision

What are the most common problems you encounter with cessation of active treatment?

- Can you give some examples that you have encountered?

- Have you ever found yourself in a situation where you did not know what to do?

- Please describe the situation.

- How did you feel?

- Did you have support?

Do you think something should be improved in intensive care units regarding cessation of active treatment and end-of-life decisions?

- What would that be?

3. General questions

Do you think that giving up / not starting, stopping / stopping active treatment are (ethically) identical procedures?

Do you think that procedures for active shortening life in the hopelessly ill are ethically justified?

What are all the pros and cons of actively shortening life in hopelessly ill people?

F. Conclusion

Is there anything else you think is important that we haven't talked about so far?

Of all the things we have talked about, what do you consider the most important?

G. Giving thanks

Thanks again for participating. I hope it was not overly demanding and that you enjoyed it. I remind you once again that the confidentiality of this conversation is absolute, and I ask you not to share everything you have heard here today from your colleagues with others outside this group. 
and eleven nurses came from ICU units linked to internal medicine and surgical departments. None of the participants came from ICU units linked to neurological departments (Table 2). All the participants were educated in Croatia.

Each focus group session lasted from forty to one hundred minutes. Altogether, five and a half hours of qualitative data were collected from the focus group sessions with physicians, and five and a half from the focus group sessions with nurses. An overview of the main themes and subthemes, with the related practical examples and supporting evidence, identified from the analysis of the physicians' focus groups, is displayed in Table 3. An overview of the main themes and subthemes from the nurses is displayed in Table 4.

\section{Physicians' Focus Groups}

Specific Context of Care

Legal

In all the focus group discussions with physicians the inadequacy of the current legal framework was
Table 3 Overview of the main themes and subthemes for physicians

\begin{tabular}{ll}
\hline Main Theme & Subtheme \\
\hline Specific context of care & $\begin{array}{l}\text { Legal } \\
\text { Sociocultural } \\
\text { Healthcare and organizational } \\
\text { Pnd-of-life decision- } \\
\text { making process }\end{array}$ \\
& $\begin{array}{l}\text { Peginning of the end } \\
\text { Relational aspects } \\
\text { Unmet needs and available resources } \\
\text { Burden of Decision Making }\end{array}$ \\
\hline
\end{tabular}

emphasized. The legal framework was perceived as overtly vague and restrictive-there is no legal stance that can be taken when withdrawing treatment interventions, while withholding treatment is vaguely and indecisively tolerated through regulations on informed consent (in connection to patients' right to refuse diagnostic or therapeutic procedures). Additionally, there are no clear regulations on advance directives. This situation give rise to many concerns and has a huge impact on the way end-of-life care
Table 2 Focus group participants

\begin{tabular}{|c|c|c|c|c|}
\hline Research site & Zagreb & Rijeka & Split & TOTAL \\
\hline Physicians & 6 & $9(7+2)$ & $7(3+2+2)$ & 22 \\
\hline Nurses & 8 & $8(5+3)$ & 7 & 23 \\
\hline Physicians (males) & 3 & 5 & 4 & 12 \\
\hline Physicians (females) & 3 & 4 & 3 & 10 \\
\hline Nurses (males) & 2 & 1 & 1 & 4 \\
\hline Nurses (females) & 6 & 7 & 6 & 19 \\
\hline $\begin{array}{l}\text { Physicians } \\
<5 \text { years of experience }\end{array}$ & 1 & 3 & 2 & 6 \\
\hline $\begin{array}{l}\text { Physicians } \\
5<\text { years of experience }\end{array}$ & 5 & 6 & 5 & 16 \\
\hline $\begin{array}{l}\text { Nurses } \\
<5 \text { years of experience }\end{array}$ & 4 & 2 & 3 & 9 \\
\hline $\begin{array}{l}\text { Nurses } \\
5<\text { years of experience }\end{array}$ & 4 & 6 & 4 & 14 \\
\hline $\begin{array}{l}\text { Physicians } \\
\text { "stand alone" ICU }\end{array}$ & 4 & 4 & 3 & 11 \\
\hline Physicians internal/surgical ICU & 2 & 5 & 4 & 11 \\
\hline $\begin{array}{l}\text { Nurses } \\
\text { "stand alone" ICU }\end{array}$ & 2 & 6 & 4 & 12 \\
\hline $\begin{array}{l}\text { Nurses } \\
\text { internal/surgical ICU }\end{array}$ & 6 & 2 & 4 & 11 \\
\hline
\end{tabular}


Table 4 Overview of Main Themes and Subthemes for Nurses

\begin{tabular}{ll}
\hline Main Themes & Subthemes \\
\hline Centrality of patient care and experience & Patient experience and vulnerability \\
& Awareness of the futility and disproportionality of care \\
& Patient advocacy \\
Being a care provider & Personal involvement and experiences \\
& Role ambiguity and conflict \\
& Serial inconsistency \\
& Emotional burden \\
Being part of a team & Interprofessional communication and decision-making \\
& Invisible heuristics \\
& Importance of leadership \\
\hline
\end{tabular}

issues are dealt with. The notion of moral distress was commonly invoked, as there is a discrepancy between what physicians consider ethical and the possibilities they have according to the law. This also creates many tensions in the relationship with the patient's family members and surrogate decision-makers. As emphasized, the current situation is a fertile ground for defensive practices within end-of-life issues and displays a complete disregard for the existence of end-of-life situations a patient may encounter in the process of healthcare delivery. The current legal framework considers patient survival as the ultimate goal of every healthcare intervention.

\section{Sociocultural}

There seems to be high variability in values and attitudes towards end-of-life issues (among patients, their representatives, and healthcare staff). It was stressed that personal values play a crucial role in end-of-life decision-making as well as previous professional and personal experiences. It is a perception of physicians that for many patients and their families, end-of-life issues are a "taboo topic" (a few of the respondents mentioned that the initiation of this discussion with family members was perceived as "giving up" on the patient). This situation also creates tension between decision-makers and commonly forces physicians to question and weigh (and finally potentially override) surrogate decision motives and decisions.

\section{Healthcare and Organizational Aspects}

Many different organizational influences on endof-life issues were discussed. Among the most prominently mentioned were: the lack of palliative care resources and facilities (only one research site has a palliative team within the institution); different and changing unwritten local rules, hierarchies, and established patterns of care (affecting triage, admission, and release from the ICU); different interprofessional (the differing values and focuses of nurses and physicians) and intraprofessional (the differing values and focus of intensive care specialists and other specialists) perspectives. All these organizational issues seem to have a critical influence on how endof-life decisions are made, incorporated, and dealt with. High workloads and the growing issue of staff shortages, which lead to many competing priorities, were emphasized as the most urgent issues within this subtheme.

\section{The End-of-Life Decision-Making Process}

Patients as Unique Individuals

The uniqueness of individual patients was a subtheme that emerged from discussions on prognosis and clinical uncertainty. Chances of survival (also referred to as treatment potential) and quality of life were regarded almost unanimously as guiding principles of care in the ICU. The issue of disentangling and incorporating objective information in the endof-life decision-making process was also prevalent. The role of nurses in representing the patient's voice and their suffering was firmly recognized by physicians, although there were different opinions on how reliable and critical this information is. Finally, the need for an individual approach to every patient was 
expressed and the need to always keep in mind the best interest of the patient. Knowing the patient and the patient's wishes was an extenuating circumstance, but nevertheless, physicians often felt that they are the ones that need to make decisions on behalf of the patient.

\section{The Beginning of the End}

The transition through curative, intensive, palliative, and end-of-life care is emotionally and cognitively engaging for physicians. All the participants stated that when there was any doubt (regardless of its source) physicians should initiate treatment. Physicians perceived that they are the ones that usually initiate the end-of-life discussion, while commonly relying on input from other healthcare team members. In that sense, the input provided from nurses was regarded as valuable, but here it was more important "who" was saying something than "what" was being said. Input from family members was also considered, but many physicians raised their concerns (while giving many examples) about the validity of surrogate decision-makers' claims (especially in cases of specific family dynamics). Here the notion of withholding certain information was introduced, as it was considered that it was unethical even to discuss care that was considered as disproportionate and futile. However, being aware of and being able to understand and incorporate the values, motivations, and beliefs of all included was considered a crucial skill when leading end-of-life discussions. The procedures and actions that physicians could provide when consensus was reached about the need to end a patient's life varied substantially. However, any intentional life terminating procedures, being strictly forbidden by law, were out of the question (with the repeated impression gained by focus group moderators that even theoretical discussion of these issues was unwelcome). As for withdrawing treatment, the notion of "basal therapy" was invoked most commonly-meaning that no new extraordinary interventions are introduced (the definition of what constitutes "extraordinary" was highly individually variable), while current ones are downsized "to an acceptable minimum." Withholding was almost exclusively reserved for cases of chronic patients with a previously diagnosed life-terminating illness, when all treatment modalities had already been exhausted. Even in those cases, there was high variability about which procedures could be considered in that sense, and how, when, and by whom these decisions should be made. In those situations, treatment of pain and suffering was considered to be the primary aim, although here also practice seems to be variable, in relation to the possible side-effects of the treatment of pain e.g. the shortening of life.

\section{Relational Aspects}

Relational aspects of end-of-life issues and decision-making were spread through many different subthemes. However, the analysis revealed a specific subtheme comprised of different relational levels that are of critical importance for end-of-life issues: the fiduciary relationship with patients and family members, and professional relationships that include interprofessional and intraprofessional relationships within the ICU and within the broader institutional context. Within the fiduciary relationship, the importance of addressing and encouraging the patient's autonomy was stressed, although to a varying degree in different research sites. The specific issue commonly mentioned here was the inadequate legal framework that does not allow patients to express their autonomy in the first place. The need to engage the patient's voice and perspective, as well as those of the patient's family, was considered a shared goal. Nurses were perceived as equally important stakeholders in decision-making, but the actual integration of their input was perceived as extremely variable. The issue of who is in charge of patient care among the many specialists involved in healthcare delivery for the patient was most prominent within surgical ICUs. Here the lack of a holistic approach to the patient, the inability to recognize the patient's prognosis, the narrow focus on physiological objectives, and conflicting values and opinions (most commonly regarding prognosis and treatment options) were observed. The perception was expressed that the specialist (outside the ICU) who referred the patient to the ICU has control over life-sustaining decision-making. In these situations, ICU specialists' loss/lack of control over the treatment process was often present. However, these disagreements have been addressed by implementing more structured decision-making processes. The importance of shared 
goals, understanding, and perspectives of end-oflife issues was stressed but also the fact that they are hard to attain in practice. Additionally, other sources, consequences, and strategies, to mitigate disagreements and conflicts, were also discussed in detail. The special issue of the lack of continuity in relationships between intensivists was put forth as highly problematic, in particular postponement or changes to end-of-life decisions previously made by an ICU team and communicated to the patient's family, at the discretion (commonly invoking the conscientious objection principle) of an individual physician (currently responsible for the care of the patient). Only one institution had developed and implemented a specific protocol to deal with continuity of care issues, where decisions were made including all the ICU staff involved in the patient's care and written into the patient's chart.

\section{Unmet Needs and Available Resources}

A more adequate legal framework was emphasized as the most obvious unmet need. Many of the issues in the care that physicians provide arise from the lack of clear guidance. However, physicians thought that influencing and improving legal regulations is out of their reach. Additionally, inadequate training in end-of-life issues was stressed, especially regarding ethics, and skilled and timely communication with patients and other healthcare workers. The needs of the ICU team were also stressed as important, as their work was perceived as highly stressful and burnout is prevalent. Physicians commonly felt that, due to various organizational and resource shortcomings, they need to "stretch themselves" in order to deliver adequate care. This was most often related to the lack of adequate palliative care but also wrongful conceptions of what intensive care is, held by other healthcare professionals, hospital management, and policymakers (the ICU is commonly perceived as "a place for dying").

\section{Burden of Decision-Making}

The emotional but also the cognitive burden of making finite decisions (bearing the final responsibility for a decision) was considered to be substantial and highly influential on future physicians' attitudes and behaviours. In this sense, the experience of unexpected patient deaths and/or survival was highlighted. Despite being aware of the ethical norms at stake, a common attitude was that "ethics does not provide you with any comfort." The need for more adequate approaches to grieving was expressed.

\section{Nurses’ Focus Groups}

Centrality of Patient Care and Experiences

\section{Patient Experience and Vulnerability}

The nurses focused more than the physicians on the patient's experience. In that sense, nurses reported that, alongside taking care of a patient's physiological functions, they placed a similar emphasis on the patients' experience, as well as the experience of the patient's family and close friends. To nurses this seemed to be an obvious and inevitable part of their work, since they are the ones that spend the most time with patients and are most closely involved in their care and treatment. In that sense nurses have the urge to humanize the care setting for their patients and their loved ones and a very common perception was that the ICU setting is extremely dehumanizing and technical.

\section{Awareness of the Futility and Disproportionality of Care}

It was quite a common perception among nurses that some of the care provided was unnecessary, disproportionate to the patient's needs and wishes, and futile. In some research sites this was mentioned very often. In these situations, the nurses either tried to initiate a discussion in the healthcare team (this was the most common strategy among more experienced nurses) or took a submissive stance. In the latter case, some nurses reported the ability to "switch off," in the sense that they were just following orders. Nonetheless, such situations provoke high levels of stress for the nurses and later on influence their relationship with the patient and their loved ones (in those situations they were more prone to delegate the questions to the physicians and generally to be less involved). 


\section{Patient Advocacy}

Quite a prominent finding that emerged from the focus group discussions was the obligation felt by nurses in representing the patients' voices and experience. This was also most prominent among more experienced nurses, who were more confident in their perceptions, and more skilful in communicating their impressions to physicians. Nurses felt that it was their responsibility to speak up for the patient and to represent the patient's voice, especially of the vulnerable. The invisible heuristics nurses develop over years in practice and working with other healthcare team members play a crucial role in this process. In other words, despite the existence of different, formal and informal channels and meetings, nurses deliberately choose when and which information they provide to a certain physician. They believe that this has a huge impact on how end-of-life discussions are conducted and on how decisions will be made. In contrast, regarding information about technical or physiological aspects of care, there was no such "weighing" in place.

\section{Being a Care Provider}

\section{Personal Involvement and Experience}

Nurses reported different levels of involvement with different kinds of patients. The most emotionally engaging patients were young ones, without previous illnesses. On the other hand, older patients that had gone through various medical interventions were perceived as less engaging. Additionally, previous personal experiences played a significant role here, as nurses who had had previous personal experience caring for their own critically ill loved ones had different perspectives on end-of-life issues. They perceived these personal experiences as "mind opening." This kind of previous personal experience made nurses more aware of the possible inappropriateness and disproportionality of certain treatment interventions and they were more prone to speak up and express their concern about those issues. Additionally, nurses were generally more prone to stress the importance of personal values and beliefs when making end-of-life decisions. This was especially prominent in less experienced nurses, who often invoked external, absolute authority (God) as being ultimately responsible for the dying process. More experienced nurses were more confident in their previous experience, personal and/or professional, and more prone to recognize various influences on the decision-making process, as well as the importance of other factors than strictly medical ones.

\section{Role Ambiguity, Conflict, and Serial Inconsistency}

Although it was also quite variable between the different research sites, nurses often reported many conflicts that arise regarding their role as a nursing professional, their role and relationship with patients and families, and within the team. This was most evident in sites with open-door policies, where there are no or few restrictions on family visits to the ICU. In these settings and situations, nurses often experience conflicts between caring for patients' predominantly psychological needs (what they consider to be their primary task as part of the healthcare team) and the psychosocial needs of the patients' family members. Nurses also reported issues with the specific dynamics of patients' families and commonly in those situations they perceived themselves as being "left on their own." Additionally, nurses commonly reported an immense conflict between their personal and professional selves. In that sense, one nurse described her work as a "balancing act" between different needs and factors, including herself. One very specific issue that emerged here was the conflict arising when following prior decisions with which they did not agree or did not take part in and in situations when decisions previously made by physicians or a team were overruled by other physicians (often occurring during shift work).

In the focus group discussions, different strategies for how nurses make sense of the care they provide were often mentioned. This was most obvious in situations when nurses were having problems understanding the treatment plan and objectives. An additional issue stressed here was the inability to understand patients' outcomes (lack of knowledge of what happens to patients after they leave the ICU).

\section{Emotional Burden}

Working at the bedside of critically ill patients was unanimously perceived as emotionally burdensome. 
Different concepts were invoked during the discussions that came under this category, such as: emotional fatigue, emotional exhaustion, distress, burnout, etc. Many different antecedents, mediators, and consequences for such phenomena were discussed. There was a widely shared opinion that such phenomena have strong influence on patients, families, healthcare professionals, and organizational outcomes. Similarly, the unanimous perception was that these issues are not handled adequately, if at all. However, it was stressed that this was an unavoidable part of their work, and mostly informal, relational networks among nurses were used to alleviate personal negative consequences.

\section{Being Part of a Team}

\section{Interprofessional Communication and Decision-Making}

The nurses' perception was that the decision-making process is mostly influenced by physicians, while also stressing their final responsibility for decisions made. In that sense, nurses reported physicians making decisions without paying enough attention to other sources of information, including the patients, the patients' loved, and other health team members. Nurses thought that equal importance should be placed on emotional and psychosocial dimensions when making end-of-life decisions, while, at the same time, these are often disregarded. In that sense, nurses seem to introduce a certain emotional and psychosocial dimension to the end-of-life decision-making process, while physicians are more focused on the physiological and more technical aspects of care. There was high variability between the different research sites regarding the inclusion of nurses' input in the decision-making process. Often, nurses reported a lack of recognition from other healthcare team members of their efforts in caring for patients. Similarly, different perceptions by nurses and physicians of the quality of their collaboration were stressed (physicians being more satisfied and more prone to see collaboration as adequate). Nurses also stressed difficulties following decisions when they were abruptly changed, commonly by a single physician. Here the emphasis was placed on the need for developing, communicating, and documenting a firm consensus and a shared understanding about the treatment plan for individual patients. Also, certain issues specific for interpersonal relationships between nurses were brought up, such as a harsh initiation period (commonly described as a "baptism of fire") and the importance of supportive informal relationships, in an emotional and instrumental sense.

\section{Invisible Heuristics}

The content of this sub-theme was spread throughout and appeared in many discussions and was found in the analysis of many sub-themes, but it finally crystalized as a distinct, separate sub-theme. It is related to the special meta-cognition ("gut-feeling") which nurses develop through years of clinical practice. The experience that counts here is not only related to patient care but also to all the cumulative experience of working in a specific organizational and broader sociocultural context. Nurses reported being able to predict decisions regarding patient care, on the basis of which physician was initiating and leading the discussion or deciding. This was mentioned as crucial for the final success of implementing their input, although it was emphasized that this is difficult to teach, as each nurse finds her/his "own way." Finally, nurses seem to assign a certain level of accountability to each physician, as well as to the decisions and actions they make. Accountability is assigned and this substantially influences how they later deal with, perform, and implement the decisions made.

\section{Importance of Leadership}

The crucial importance of leadership was commonly stressed. It was perceived that their immediate medical superior, the head of the department, sets the tone, pace, and culture for the whole unit. This culture is perceived as highly important and having a huge effect on clinical work, but also relational, ethical, and affecting all other aspects of their everyday practice. As such, it also has an influence on patient-related and healthcare staff-related outcomes, as well on how end-of-life decisions are initiated, handled, made, and followed. 


\section{Discussion}

The aim of this study was to explore the perceptions and experiences of healthcare professionals with end-of-life decisions in ICUs in tertiary healthcare institutions in Croatia. End-of-life decisions were faced on almost a daily basis by the study participants, although this varied between different ICU units. The analysis revealed significant differences between healthcare professional groups.

Nurses' experiences and perceptions were more narrowly focused on the patient beneficence, nonmaleficence, and autonomy, the immediate treatment context, and their involvement in the care and decision-making process, as well as the consequences that care and involvement have for them in a personal and professional sense. Common concerns expressed by nurses were respect for patient's dignity, proportionality of care, and their inability to signal and incorporate their input in the decisionmaking process (Farrell 2006; Jensen et al. 2013). Also, in line with findings from the literature, nurses' previous professional and clinical experience had a significant impact on their perception of end-of-life issues (Raijmakers et al. 2011; Latour, Fulbrook, and Albarran 2009; McMillen 2008; Sevdalis and Brett 2009). This was mostly related to the sub-theme "invisible heuristics," where nurses reported that they had gradually developed an inner, gut feeling on how to signal and incorporate their perspectives in decision-making processes that were perceived as being mostly led by physicians. Although similar themes could be found in the literature on end-of-life issues in ICUs, this finding is, to our knowledge, the first one singling out a possible specific mediator, the nurses' "experience effect" on end-of-life decisions (Sevdalis and Brett 2009; Edmondson, et al. 2016; Bloomer and O'Connor 2012; Lobo, et al. 2017). The importance of the various negative effects of work in the ICUs was significantly more prominent in discussions with nurses. Negative effects (emotional fatigue, moral distress, burnout) were most prominent in situations when nurses had the feeling that they needed to follow orders they were not at ease with, did not understand, or considered to be inappropriate (Flannery, Ramjan, and Peters 2016; St Ledger, et al. 2012; van Mol, et al. 2015; Shoorideh, et al. 2015; Lief, et al. 2018; Hua, et al. 2016).
On the other hand, the physician's perspective could be considered as broader, also involving a wider context and emphasizing their final responsibility for initiating, facilitating, and implementing endof-life decisions. However, autonomy of the patient, respect for patient's dignity, beneficence, and nonmaleficence, proportionality of care but also ethical principles of professional duty, transparency (having good and adequate medical records and guidance for end-of life decision-making) were also prevalent in discussions. This finding seems natural and reflective of the clinical and professional roles physicians have in the healthcare system (Curtis and Vincent 2010; Sprung et al. 2014; Forte, et al. 2012). Physicians were more concerned by the effects of different intraprofessional relationships than interprofessional ones, and they reported disagreements with physicians with other medical specialties that were/had been somehow involved in the care of a patient. The importance of leadership was also emphasized, and it seems that medical leaders (both the immediate and more distant ones) have a huge impact on the overall culture but also on specific, local patterns of care. Different levels and layers of intraprofessional hierarchies play an important role in how end-of-life decisions are dealt with (Flannery, Ramjan, and Peters 2016; Westphal and McKee 2009; Forte, et al. 2012).

It is important to notice that discussions about any intentional life-terminating procedures, even theoretical ones, were considered as unwelcome by the participants. The most common answer in this regard was that this is a form of murder or euthanasia and that it is against the law. Physicians were more prone to consider withdrawing or withholding treatment interventions as morally equivalent procedures, but nurses considered withholding as less acceptable. A common explanation used by nurses was that it is better to start and then to stop when an intervention is not doing any good than not to start at all. Considering the previous literature, this is quite an interesting finding, as in most of the literature, withdrawing and withholding are considered to be equivalent (Sprung, et al. 2014; Joynt, et al. 2015; Myburgh, et al. 2016; Downar, et al. 2016; Gopalan and Pershad 2019).

Among both professional groups a widely expressed concern was the inability to externalize control of decision-making to patients and their families. As in the research done by Jukic et al. (2016), this was related to the specific legal framework, since 
there is no legal ground for advance directives in Croatia.

\section{Conclusion}

This was the first focus group research done in ICUs in Croatia on the perceptions, experiences, and challenges healthcare professionals face when dealing with end-of-life decisions. Many important common features of the experience with end-of-life issues were emphasized by nurses and physicians. However, the focus and weight these professional groups assign to specific features and issues varied greatly. Nonetheless, the pressing need to create a more adequate legal framework, as well as professional and clinical guidelines, was omnipresent. Currently there is high, to a similar extent intra- and inter- variability between healthcare professionals and their practices, and as such they are highly dependent on various personal, relational, and contextual influences. The VAL-DEEND project, of which this focus group research is a part, has the drafting of possible end-of-life guidelines for the ICU setting in Croatia as one of its outputs. At the end of the project, when all the research has been analysed, the interdisciplinary project team will try to draw up draft guidelines. We will draw from the experiences of our Slovenian colleagues who have already drafted similar guidelines. Moreover, within the project we have already conducted a systematic review of ethical content of expert recommendations for end-of-life decision-making in ICUs. The following themes were highlighted in the majority of the reviewed documents and should therefore, with the others that will be additionally highlighted within this project, be part of future guidelines: respect for patients' rights, wishes, and values, consideration of family and surrogate decision-makers wishes, adequate provision of information to patients and surrogate decision-makers, importance of psychosocial needs of patients and families, regular evaluation of treatment goals, importance of keeping good medical records (transparency), team decisionmaking based on consensus, non-interference of ICU team's values with those of patients and families, importance of palliative care provision, and clarification of withholding and withdrawing of treatment (Spoljar, et al. 2020).
These guidelines are of great importance since Croatia, like other European countries, has experienced a surge in COVID-19 cases and death rates in ICUs, with possibly many other issues occurring that are not explored by our research. Moreover, further research is needed to investigate the impact of the COVID-19 pandemic on the perceptions, experiences, and challenges healthcare professionals face when dealing with end-oflife decisions in ICUs in Croatia.

\section{Limitations}

This study has several limitations, mostly regarding the sampling methods used, concerns regarding possible under-representation, and the lack of generalizability. The purposive sampling method was used in order to secure a sufficient number of participants that would conform to our inclusion criteria at each research site. However, this method of sampling has well-known limitations that may have a smaller effect if the target population is not large, if the topic is rich, and generally if used in qualitative research. This focus group study was only conducted in ICUs in hospitals at the tertiary level of healthcare in Croatia. Physicians and nurses from smaller ICUs in regional hospitals were not part of the study. Therefore, there is a need for further research of the perceptions, experiences, and challenges healthcare professionals face when dealing with end-of-life decisions in ICUs at a regional level in Croatia. Moreover, our research did not cover ICUs at the tertiary level of healthcare in the eastern part of Croatia, since approval from the ethical committee at Osijek Clinical Hospital Center was not obtained. However, these findings may be considered valid, as a significant number of participants were included and all the other sites were well represented. Finally, our study was conducted prior to the outbreak of the COVID-19 pandemic, and we were therefore unable to look into the new reality in the light of the additional changes that the COVID-19 pandemic has caused to the organization and everyday work of Croatian ICUs.

\section{References}

Anderson Shaw, L.K., and F.A. Zar. 2020. COVID-19, moral conflict, distress, and dying alone. Journal of Bioethical Inquiry 17(4): 777-782.

Bloomer, M., and M. O'Connor. 2012. Providing end-oflife care in the intensive care unit: Issues that impact on 
nurse professionalism. Singapore Nursing Journal 39(38): 25-30.

Bowen, G.A. 2008. Naturalistic inquiry and the saturation concept: A research note. Qualitative Research 8(1): 137-152.

Curtis, J.R., and J.L. Vincent. 2010. Ethics and end-of-life care for adults in the intensive care unit. Lancet 376(9749): 1347-1353.

Degoricija, V., S. Sefer, M. Kujundzic-Tiljak, and M. Gjurasin. 2002. Intensive care units in Croatia: 2001 survey. Croatian Medical Journal 43(6): 713-721.

Deyaert, J., K. Chambaere, J. Cohen, M. Roelands, and L.Deliens. 2014. Labelling of end-of life decisions by physicians. Journal of Medical Ethics 40(7): 505-507.

Denzin, N.K., and Y.S. Lincoln. 1994. Handbook of qualitative research. Thousand Oaks, CA: Sage Publications.

Downar, J., J.W. Delaney, Hawryluck L.L., and L. Kenny.2016. Guidelines for the withdrawal of life-sustaining measures. Intensive Care Medicine 42(6): 1002-1017.

Edmondson, A.C., M. Higgins, S. Singer, and J.Weiner. 2016. Understanding psychological safety in health care and education organizations: A comparative perspective. Research in Human Development 13(1): 65-83.

Flannery, L., L.M. Ramjan, and K. Peters. 2016. End-of-life decisions in the Intensive Care Unit [ICU]-Exploring the experiences of ICU nurses and doctors-A critical literature review. Australian Critical Care 29(2): 97-103.

Farrell, B. 2006. Understanding the moral distress of nurses witnessing medically futile care. Oncology Nursing Forum 33(5): 922-930.

Forte, D., J.L. Vincent, I.T. Velasco, and M. Park.2012. Association between education in EOL care and variability in EOL practice: A survey of ICU physicians. Intensive Care Medicine 38(1): 404-412.

Glaser, B.G., and A.L. Strauss. 2009. The discovery of grounded theory: Strategies for qualitative research. New York, NY: Aldine Publishing Company.

Gopalan, P.D., and S. Pershad.2019. Decision-making in ICU-a systematic review of factors considered important by ICU clinician decision makers with regard to ICU triage decisions. Journal of Critical Care 50(April): 99-110.

Grosek, S., M Orazem, and U. Groselj. 2018. Notes on the development of the Slovenian Ethical Recommendations for Decision-Making on Treatment and Palliative Care of Patients at the End of Life in Intensive Care Medicine. Paediatric Critical Care Medicine 19(8S Suppl 2): S48-S52.

Groselj, U., M. Orazem, M. Kanic, G. Vidmar, and S. Grosek. 2014. Experiences of Slovene ICU physicians with endof-life decision making: A nation-wide survey. Medical Science Monitor: International Medical Journal of Experimental and Clinical Research 20: 2007-2012.

Grove, R.W. 1988. An analysis of the constant comparative method. International Journal of Qualitative Studies in Education 1(3): 273-279.

Hewitt-Taylor, J. 2001. Use of constant comparative analysis in qualitative research. Nursing Standard 15/42): 39-42.

Hrstic, D. 2016. Anticipirano odlučivanje pacijenta [Anticipated patient decision making]. Zagrebačka pravan revija [Zagred Legal Review] 5(1): 11-36.

Hua, M., S.D. Halpern, N.B. Gabler, and H. Wunsch.2016. Effect of ICU strain on timing of limitations in life-sustaining therapy and on death. Intensive Care Medicine 42(6): 987-994.

Jensen, I., J. Ammentorp, H. Johannessen, and H. Ørding. 2013. Challenges in end-of-life decisions in the intensive care unit: An ethical perspective. Journal of Bioethical Inquiry 10(1): 93-101.

Joynt, G.M., J. Lipman, C. Hartog, et al. 2015. The Durban World Congress Ethics Round Table IV: Health care professional end-of-life decision making. Journal of Critical Care 30(2): 224-230.

Jukic, M., L. Saric, I. Prkic, and L. Puljak. 2016.Medical futility treatment in intensive care units. Acta Medica Academica 45(2): 127-136.

Latour, J., P. Fulbrook, and J.W. Albarran. 2009. EfCCNA survey: European intensive care nurses' attitudes and beliefs towards end-of-life care. Nursing Critical Care 14(39): 110-121.

Lief, L., D.A. Berlin, R.C. Maciejewski, et al. 2018. Dying patient and family contributions to nurse distress in the ICU. Annals of American Thoracic Society 15(17): 1459-1464.

Lobo, S.M., F.H.B. De Simoni, S.M. Jakob, et al. 2017. ICON investigators. Decision-making on withholding or withdrawing life support in the ICU: A worldwide perspective. Chest 152(2): 321-329.

McMillen, R. 2008. End-of-life decisions: Nurses perceptions, feelings and experiences. Intensive and Critical Care Nursing 24(1): 251-9.

Myburgh, J., F. Abillama, D. Chiumello, et al. 2016. Endof-life care in the intensive care unit: Report from the Task Force of World Federation of Societies of Intensive and Critical Care Medicine. Journal of Critical Care 34: $125-130$

Orfali, C. 2020. What triage issues reveal: Ethics in the COVID-19 pandemic in Italy and France. Journal of Bioethical Inquiry 17(4): 675-679.

Raijmakers, N.J., L. van Zuylen, M. Costaninin, et al. 2011. Issues and needs in end-of-life decision making: An international modified Delphi study. Palliative Medicine 2(7): 947-953.

Sevdalis, N., and S.J. Brett. 2009. Improving care by understanding the way we work: Human factors and behavioural science in the context of intensive care. Critical Care 13(2): 139.

Shoorideh, F.A., T. Ashktorab, F. Yaghmaei, and H. Alavi Majd. 2015. Relationship between ICU nurses' moral distress with burnout and anticipated turnover. Nursing Ethics 22(1): 64-76.

Sladic, H. 2015. Kaznenopravno uređenje usmrćenja na zahtjev i asistiranog suicida [Criminal regulation of on-demand killings and assisted suicide]. Godišnjak Akademije pravnih znanosti Hrvatske [Yearbook of the Croatian Academy of Legal Sciences] 6(1): 63-100.

Sorta-Bilajac, I., K. Bazdaric, B. Brozovic, and G.J. Agich. 2008. Croatian physicians' and nurses' experience with ethical issues in clinical practice. Journal of Medical Ethics 34(6): 450-455.

Sprung, C.L., R.D. Turog, J.R. Curtis et al. 2014. Seeking worldwide professional consensus on the principles of end-of-life care for the critically ill. The Consensus for Worldwide End-of-Life Practice for Patients in Intensive 
Care Units [WELPICUS] Study. American Journal of Respiratory Critical Care Medicine 190(8): 855-866.

Spoljar, D, M. Curkovic, C. Gastmans, et al. 2020. Ethical content of expert recommendations for end-of-life decisionmaking in intensive care units: A systematic review. Journal of Critical Care 58: 10-19.

St Ledger, U., A. Begley, Reid, L. Prior L., D. McAuley, and B. Blackwood. 2012. Moral distress in end of-life care in the intensive care unit. Journal of Medical Ethics 69(8): 1869-1880.

van Mol, M.M., E.J. Kompanje, D.D. Benoit, J. Bakker, and M.D. Nijkamp. 2015. The prevalence of compassion fatigue and burnout among healthcare professionals in intensive care units: a systematic review. PLoS One 10: $\mathrm{e} 0136955$.

Vucemilo, L., M. Curkovic, M. Milosevic, J. Mustajbegovic, and A. Borovecki. 2013. Are physician-patient communication practices slowly changing in Croatia?-A crosssectional questionnaire study. Croatian Medical Journal 54(2): 185-191.
Vucemilo, L., M. Milosevic, D. Dodig, B. Grabusic, B. Đapic, and A. Borovecki. 2016. The quality of informed consent in Croatia-a cross-sectional study and instrument development. Patient Education and Counselling 99(3): 436-442.

Westphal, D., and S.A. McKee. 2009. End-of-life decision making in the intensive care unit: Physician and nurse perspectives. American Journal of Medical Quality 2(3): 222-229.

Wilkinson, D., R. Truog, and J. Savulescu. 2016. In favour of medical dissensus: Why we should agree to disagree about end-of-life decisions. Bioethics 30(2): 109-118.

Publisher's Note Springer Nature remains neutral with regard to jurisdictional claims in published maps and institutional affiliations. 